\title{
Exploring How to Ensure the Quality of Bilingual Education in Advanced Mathematics*
}

\author{
Xiuqing $\mathrm{Yu}$ \\ Department of Mathematics, Dezhou University, Dezhou 253000, Shandong, China \\ Email: sddzyxq@163.com
}

\begin{abstract}
International market and talent competition presented a higher requirement of advanced education. This paper explores how to ensure the quality of bilingual education with "Advanced Mathematics" in universities from several aspects, such as objectives, patterns, practice, and evaluation, etc.
\end{abstract}

Index Terms - bilingual education, advanced mathematics, practice, evaluation

\section{INTRODUCTION}

International market and talent competition presented a higher requirement of advanced education. To cultivate foreign language and suitable capabilities of the professional and technical personnel becomes one of the teaching goals of advanced education. Therefore, bilingual education is paid to attention increasingly in order to adapt to development needs of the trend of internationalization of advanced education, it is also an important approach to develop compound talents with international cooperation, international exchanges and competitiveness. To carry out bilingual teaching in China not only helps college students master the latest theory and cutting-edge technology quickly, but also is conducive to the introduction of foreign advanced educational resources, teaching ideas, and teaching methods. In addition, it can prompt teachers to learn continuously in order to improve the level of expertise and foreign language application.

\section{THE MEANING OF BILINGUAL EDUCATION AND ITS OBJECTIVES IN ADVANCED MATHEMATICS}

The word "Bilingual" means two kinds of language. The literal meaning of bilingual education should make use of two languages (usually with Chinese and English in China) to teach and learn. Bilingual teaching is not teaching English, nor is the teaching of English as a foreign language. It is that English only is as the second teaching language in the whole process of teaching (A teaching method of using English as the second language).The whole process of teaching should include teaching materials, teaching reference books, teacher lectures, courseware, tutoring, homework and exams and other factors.

The goal of bilingual teaching in advanced mathematics, first of all, should enable students to achieve the same knowledge and skills' objectives taught in native language, namely in Chinese. Secondly, it should achieve the basic requirements of this course. Thirdly, after taught and trained in bilingual teaching, students should improve their English level, can communicate with international scholars in the "common language" smoothly, read foreign math materials, and understand foreign math ideas and approaches. Ultimately bilingual education achieves to develop comprehensive quality of students, especially math and language quality with advanced international ideas and thinking ways.

\section{PATTERN OF BILINGUAL EDUCATION IN ADVANCED MATHEMATICS}

In teaching, the academics divide bilingual teaching pattern into three types including immersion bilingual education, maintenance bilingual education and transitional bilingual education. Immersion bilingual education is a pattern that is for teachers to teach advanced mathematics knowledge in non-native language completely. It stresses full use of English to teach professional knowledge. Maintenance bilingual education is a type of transitional study subjects that is the initial full use of mother tongue to teach, and then gradually shifted to using a second language to learn some subjects. Transitional bilingual education is more prominent of the final transition to all disciplines in a second language. To study the feasibility of three models mentioned above reasonably and realistically, maintenance bilingual education is the most suitable to Chinese current situation and conditions, because Learning environment for Chinese students is Chinese, and students' learning, thinking and other cognitive activities are in Chinese. The implementation of the "maintain the style" in bilingual education can make maximum use of existing teachers and teaching resources. Furthermore, the gradual penetration mode helps students to understand and apply the two cultures gradually.

\footnotetext{
* This research was supported by the Natural Science Foundation and the Education Science Foundation of Shandong Province of China (ZR2010AL019), and (2010JZ123) respectively.
} 


\section{PRACTICE OF BILINGUAL EDUCATION IN ADVANCED MATHEMATICS}

Advanced Mathematics is an important and basic course in University for the science and engineering students, for the course will directly affect the quality of learning to follow-up courses and graduate professional examination's success. As Bilingual teaching mathematics in China has little experience for reference. Even if we can select an excellent original textbook which is suitable to Chinese students' mathematical cognitive style, a corresponding translation versions in Chinese is relatively small. So it is very important that we can choose an original-textbook and supporting materials in Chinese. At present, the book that is pressed by Prentice 2 Hall Press in the United States, written by Dale Varberg etc. The textbook covers the content that is similar with our current mathematics. The chapters are as follows: 1. Prior knowledge, 2. Functions and limits. 3. Derivative. 4. Applications of Derivatives. 5. The integrals. 6. Integral application. 7. Transcendental functions. 8. Techniques of integration. 9. Indeterminate Forms and I mp roper Integral. 10. Infinite series. 11. Numerical methods and approximate. 12. Conics and polar coordinates. 13. Geometry in the Plane, Vectors. 14. Geometry in Space, Vectors. 15. n-dimensional space. The book has common features with other excellent textbooks by the United States- language easy to understand, focusing on the visual interpretation of concepts and theorems, focusing on students to use technology tools such as graphics calculators and mathematical software such as Maple and Matlab for visual learning-methods, focusing on integration of ideas and methods of mathematical modeling. These points coincide with the ongoing of teaching reform in Chinese domestic mathematics. Compared with other excellent materials, such as one by Thomas Tomas' Calculus, the book also has more emphasis on rigorous mathematical theory of the characteristics, which is quite similar with domestic materials. It is very suitable for bilingual education.

\section{A. Selecting Excellent Textbook and Reference Materials, and Writing Suitable Teaching-Cases}

Whether imported and domestic publication, or translation of the school's teaching has some limitation. Team of bilingual teaching mathematics should depend on students' level of English and mathematics, and write excellent teaching-cases combined with the mathematical basis, ways of students' thinking, English acceptance ability and other factors. In this way, bilingual teachers can choose the most suitable teaching approach, teaching content, and teaching speed to have their lessons. Furthermore they can adjust the foreign penetration of mathematical thinking in order to ensure maximum teaching-quality of advanced mathematics, and to achieve the goal of bilingual education requirements. On the other hand, as there are learning cases for students before class, they can clearly know important content, English nouns of Mathematics and the expression of mathematical reasoning, as well as reference information in this lesson which should be previewed. It is certainly helpful for the lesson.

\section{B. Using Advanced Teaching Methods to Stimulate Students' Interest in Learning and Communication}

Because advanced mathematics is very abstract and learning time is so little, during the implementation of bilingual education, the problem of study intension stands out in particular. Thus how to have abstract mathematical knowledge visualization, complex issues simple, boring math vivid is what mathematics teachers dedicate to do. In this situation, teachers should request students to preview English vocabulary used at the beginning of class, use multimedia electronic courseware in English for Electronic courseware for teaching can reduce time, improve teaching efficiency, and greatly help students understand and learn.

In classroom, teachers express definitions, theorems in English, explain in Chinese. In addition, to improve teaching effect of classroom, teachers should pay attention to advanced teaching-idea and methods presented in foreign materials in the teaching process, such as active learning idea, problem solving method, and group studying and other teaching methods. Meanwhile teachers should reform the traditional teaching-model of "teacher talk, students listen to", allow students to actively participate in the teaching process, maximize to mobilize the students' enthusiasm. They can encourage students to make full use of study case, the English multimedia courseware and related reference materials and supplementary materials on the web site for students to review and free supplementary learning.

\section{EVALUATION EFFECT OF BILINGUAL EDUCATION EFFECTIVELY}

Teachers can know all aspects of teaching through evaluation so that they can judge teaching effectiveness, shortcomings, contradictions and problems. Comprehensive evaluation not only can estimate students' grades, the extent of carrying out teaching goals, but also can explain the reasons for poor performance. The basis of teaching evaluation mainly refers to certain objective standards according to related and various data, teaching activities and their effects are determined by the evaluating system. Teaching evaluation is an indispensable basic one of teaching-links, which play multiple role in the teaching process, namely from the overall regulation to control the conduct of teaching activities that ensure to achieve intended goal ultimately. The role of teaching evaluation mainly in: 1. Diagnosing teaching problems. Through teaching evaluation teachers can understand whether their own teaching goals is reasonable or not, whether teaching methods and means are properly used or not, whether the teaching focus and difficult points are clarifying or not, whether students can understand the lesson. Furthermore teachers can know students' learning situation and existing problems so that they can adjust teaching strategies to improve teaching facilities in time. 2 . To provide feedback. Practice shows that the results of teaching evaluation, which not only provide a lot of feedback for teachers' judging teaching condition, but also provide direct feedback for the students' learning. 3. Incentives. The 
teaching evaluation plays the important role of supervision and control to teaching and learning process, it is to promote and strengthen for teachers and students, to reflect the teachers' teaching effectiveness and student performance. Experience and studies show that the test results which are often recorded can greatly inspire students within the limits set because students can get the psychological and spiritual encouragement to motivate them to a higher goal of the initiative as the teacher can give a higher rating; even lower rating also encourage students to think about, see the gap between themselves, and find the error and the "crux" of the where with the teachers' help. 4. Teaching function. The evaluation is itself a mathematical activity. In this activity, students' knowledge and skills will grow, even leap. Testing can be thought as an important learning-experience, which requires students to review the teaching materials in advance, consolidate and integrate mathematics skills learned before. Subsequent analysis of examination questions can confirm, clarify and correct some ideas. In addition, in the premise of estimating the students' learning teachers can give learning content in test questions' form that include some interesting topics questions in order to let students explore, comprehend, get to learn added learning -experience or to achieve higher objectives.

\section{SETTING OF MATHEMATICS CLASSES IN BILINGUAL EDUCATION}

To ensure the effectiveness of bilingual education, firstly the classes of bilingual education in advanced mathematics should be formed by students who are good at both mathematics and English, and offer to participate in bilingual education classes; Secondly, the number of students in bilingual education classes should not be more than 60 in order to facilitate the exchange.

\section{CONCLUSION}

Bilingual education is required by times, it is a good way to learn advanced teaching-philosophy, advanced teaching-methods and educational means. Mathematics is the foundation of science and engineering discipline, its bilingual education will surely benefit the bilingual teaching of other professional courses. Although the practice of bilingual teaching will meet some questions such as shortage of qualified bilingual teachers, the insufficient preparation of teaching materials, unideal language surrounding, etc., this is temporary. With the tireless efforts of educators, bilingual education will be getting better and better.

\section{REFERENCES}

[1] WANG Li-ping, (2004). Restricting Factors in Bilingual Teaching: a Positivist Analysis and the Solutions. Journal of Yangzhou University (Higher Education Study Edition), Vol.8(1) 77-80.

[2] LI Chun-mao, WU Yue- feng, LIU Yu. (2007). Research of bilingual teaching progress in China's universities. Journal of Higher Education Management, Vol.1(5) 70-76.

[3] XIA Dan. (2007). Reflections on bilingual education in universities. Journal of Southwest Agricultural University (Social Science Edition), Vol.5(1)117-120.

[4] WANG You-lian (2004). Studies on bilingual teaching for undergraduate specialized courses of finance. Journal of University of Shanghai for Science and Technology, Vol.3(3) 53-56.

[5] FENG Ping. (2009). The exploration and consideration of the bilingual teaching in C Language programming. Journal of Changchun University, Vol.19(8) 80-82.

[6] HONG Yong-ming . (2007). Constructing Bilingual Teaching Model Based on the Relations of Different Languages. Journal of Research on Education for Ethnic Minorities. Vol.18(6).39-44.

[7] ZHANG Yu-feng, ZHAO Zhi-xin, etc. (2005). Survey of Bilingual Teaching in Clinical Internship of Infectious Diseases. Northwest Medical Education, Vol.15(1) 108-110.

[8] ZHANG Tong-le, CHENG Li. (2006). Reflections on Bilingual Education in China. Journal of Anhui University (Philosophy and Social Sciences) Vol.30(1) 47-50.

[9] LIU Guo-qing, GAI Yun-ying, WANG Yong. (2006). Practice and Innovation in Mathematics Bilingual Teaching. College University, Vol.22(24) 23-25.

[10] WANG Rui, LIANG Bao-song. (2010).Practice on bilingual education in advanced mathematics. Journal of Higher Correspondence Education (Natural Sciences), Vol.23(3) 35-38.

[11] Judiy Cuisk. (2002). Innovative Techniques for Large-Group Instruction. A rlington, Virginia: NSTA Press National Science Teachers Association.

Xiuqing Yu was born in Dezhou, China in 1968. She received her M.S. degree in mathematics teaching from Shandong University, China in 2007.

She is currently an associate professor in the Department of Mathematics, Dezhou University, Dezhou, China. Her research interests include theory and application of rough system and mathematics teaching. 